\title{
O uso da ludicidade como ferramenta para o Ensino de Química Orgânica: o que pensam os alunos
}

Elaine da Silva Ramos elaine.ramos@ifpr.edu.br orcid.org/0000-0001-9224-3955 Instituto Federal do Paraná (IFPR), Telêmaco Borba, Paraná, Brasil Universidade Estadual de Londrina (UEL), Londrina, Paraná, Brasil

Fernanda Alves Campolin dos Santos

fernandacampolin@hotmail.com

Telêmaco Borba, Paraná, Brasil

\section{Carlos Eduardo Laburú}

laburu@uel.br

Universidade Estadual de Londrina (UEL), Londrina, Paraná, Brasil

\section{RESUMO}

Para a maioria dos alunos a disciplina de química é muito teórica, monótona, com muitos cálculos e, na maioria das vezes, não possui interação com seu cotidiano. Existem muitas ferramentas que podem vir a auxiliar para que o processo de ensino e aprendizagem se torne mais significativo e mais atraente para os alunos. Uma delas é a utilização de jogos e atividades lúdicas, opção escolhida, para desenvolver um projeto de PIBIC-Jr no IFPR Campus Telêmaco Borba durante o ano de 2016. O presente estudo aborda o desenvolvimento, a aplicação e a avaliação de um jogo didático e de duas atividades lúdicas para o ensino de química orgânica para uma turma de $3^{\circ}$ ano do Técnico em Informática para Internet Integrado ao Ensino Médio. Os dados foram analisados por meio de respostas a questionários e posteriormente foram categorizados para a análise dos resultados, que apontaram como o jogo e as atividades lúdicas puderam auxiliar no processo de ensino e aprendizagem, e mostraram também que essas ferramentas auxiliaram para que houvesse um maior diálogo e interação entre os alunos.

PALAVRAS-CHAVE: Ensino de Química. Lúdico. Química Orgânica. 


\section{INTRODUÇÃO}

As diretrizes que regulamentam o ensino de química propõem que ele seja trabalhado em sala de aula de forma mais divertida e dinâmica, trazendo um ambiente diversificado daquelas aulas tradicionais, para despertar maior atenção dos alunos com a disciplina e os conteúdos trabalhados. Por isso, vários trabalhos diversificados vêm sendo propostos com a intenção de melhorar a aprendizagem em química. Uma dessas propostas que vem se destacando é o uso de jogos e atividades lúdicas, descritos com frequência na literatura (CUNHA, 2012, SOARES, 2013, OLIVEIRA; SOARES; VAZ, 2015).

A ludicidade possui a habilidade de socializar e produzir prazer quando é executada. Ela apresenta-se como uma importante ferramenta de ensino e pode ser empregada como atividade formadora e informadora sobre várias temáticas. Para Soares (2004), atividades como jogos e/ou brincadeiras podem ser usadas para apresentar obstáculos e desafios a serem vencidos, como forma de fazer com que o indivíduo atue em sua realidade, o que envolve, portanto, o interesse e o despertar do sujeito, uma vez que quando se utiliza essa ferramenta:

a) a aprendizagem de conceitos, em geral, ocorre mais rapidamente, devido à forte motivação;

b) os alunos adquirem habilidades e competências que não são desenvolvidas em atividades corriqueiras;

c) o jogo causa no estudante uma maior motivação para o trabalho, pois ele espera que este lhe proporcione diversão;

d) os jogos melhoram a socialização em grupo, pois, em geral, são realizados em conjunto com seus colegas;

e) os estudantes que apresentam dificuldade de aprendizagem ou de relacionamento com colegas em sala de aula melhoram sensivelmente o seu rendimento e a afetividade;

f) os jogos didáticos proporcionam o desenvolvimento físico, intelectual e moral dos estudantes;

g) a utilização de jogos didáticos faz com que os alunos trabalhem e adquiram conhecimentos sem que estes percebam, pois a primeira sensação é a alegria pelo ato de jogar (CUNHA, 2012, p. 95-96).

O jogo, de acordo com a literatura, pode ter duas funções distintas: a educativa e a lúdica. Quando apresenta somente o objetivo de ensinar é considerado educativo, mas se também apresentar a função de diversão, pode ser considerado lúdico. A intenção quando se trabalha com os jogos é que eles estejam equilibrando essas duas funções, a educativa e a lúdica. Porque se não apresentar a função educativa ele apenas será um jogo como qualquer outro que existe, e também se apenas for lúdico será um jogo pelo jogo, sem ter um caráter educacional.

A diferença que existe entre o jogo e a atividade lúdica está na forma pela qual a atividade é executada. Enquanto no jogo existe uma ordem e regras, as atividades lúdicas podem gerar comportamento livres e com bastante observação, como, por exemplo, na utilização em história em quadrinhos ou teatros. 
Com o uso do lúdico poderá ser possível envolver o aluno em sua própria aprendizagem, dentro dos seus limites, de suas possibilidades e do seu conhecimento. Assim, fazendo com que ele descubra prazer em aprender e estudar, pois essa ferramenta não eliminará a complexidade do ensino de química, mas poderá contribuir com o professor em sala de aula e favorecer para o aluno melhor compreensão dos conteúdos, concorrendo para o aumento do seu interesse, que, por sua vez, pode sentir-se mais confortável com uma ferramenta dinâmica durante as aulas de química.

Entre os diversos conteúdos que podem auxiliar nesse processo destacamse os que estão presentes na Química Orgânica, "pois vivemos em uma época onde o papel principal da química orgânica na medicina, na bioengenharia, na nanotecnologia e em outras disciplinas é mais aparente que nunca" (SOLOMONS; FRYHLE, 2005, p. 2). Além de ser a parte que estuda os compostos do carbono, sendo eles centrais para a vida de nosso planeta.

A Química Orgânica está relacionada com vários compostos que fazem parte da estrutura de várias substâncias químicas encontradas em nosso cotidiano. Esses compostos além de possuírem várias aplicabilidades, também apresentam características específicas para cada função. E essas funções classificadas de acordo com a sua estrutura e propriedades físicas e químicas semelhantes.

Segundo Pazinato et al (2012), mesmo a química orgânica estando intrinsecamente relacionada com a vida, a maioria dos professores do ensino médio ainda tem muitas dificuldades em contextualizar os conteúdos curriculares dessa disciplina em suas aulas. Na realização do projeto objetivou-se trabalhar a química orgânica de forma contextualizada com a realização do jogo, pois as funções orgânicas geralmente são trabalhadas somente por meio de memorização da sua nomenclatura, sem estabelecer as relações que existem com o cotidiano dos alunos.

Nas atividades lúdicas realizadas com os alunos buscou-se trabalhar com materiais alternativos e de custo baixo. Por exemplo, o uso de bexigas para trabalhar o conceito de hibridização do carbono e geometria das moléculas; assim como os palitos de dente e balas de goma para trabalhar com os tipos de isomeria.

O objetivo deste trabalho é apresentar as etapas do desenvolvimento, aplicação e avaliação do projeto de PIBIC-Jr, que teve como finalidade trabalhar a química por meio do lúdico, desenvolvido no IFPR Campus Telêmaco Borba com alunos do $3^{\circ}$ ano do Técnico em Informática para Internet Integrado ao Ensino Médio.

De acordo com Soares (2016),

Ainda há poucos grupos trabalhando na área de jogos em ensino de química, sempre incorremos em produções endógenas, ou seja, as mesmas pessoas quase sempre publicando trabalhos com os mesmos vieses, o que dificulta o crescimento da área (SOARES, 2016, p.13).

Com a produção de mais trabalhos e sujeitos envolvidos existirá a possibilidade de amplificação dessa área do ensino de química. Este trabalho poderá auxiliar no processo de divulgação da ludicidade no ensino de química, colaborando para que a área cresça e se fortaleça. 


\section{METODOLOGIA}

Primeiramente, aplicou-se um questionário composto por seis questões abertas, que foi respondido individualmente, já que era necessário que cada aluno expressasse seus conhecimentos e suas concepções sobre o assunto proposto. 0 objetivo dele foi identificar se os alunos possuíam conhecimentos sobre jogos e atividades lúdicas; quais as dificuldades possuíam em relação à disciplina de química; sobre a metodologia utilizada pelo professor em sala de aula; se gostariam de utilizar os jogos e as atividades lúdicas na disciplina e quais seriam os que gostariam de trabalhar em sala de aula.

Utilizou-se o questionário, pois de acordo com Fiorentini e Lorenzato (2009), ele é um instrumento de coleta de dados que contém um conjunto de perguntas, podendo estas serem abertas ou fechadas. Para Moreira e Caleffe (2008), o questionário possui vantagens aos interessados em pesquisar a sua própria prática pedagógica, como a eficiência do tempo, o anonimato para o respondente, alta taxa de retorno, o que se enquadra no tipo da presente pesquisa.

Depois de aplicado o questionário, os dados foram categorizados e agrupados por unidades de significado de acordo com as semelhanças e divergências, considerando os objetivos de cada questão proposta. Para isso, utilizou-se a metodologia de análise de conteúdo de Bardin (2002, p.15): "um conjunto de instrumentos metodológicos que se aperfeiçoa constantemente e que se aplicam a discursos diversificados". Essa análise foi utilizada como meio para revelar o que parece estar oculto no texto e irá fazer uma decodificação da mensagem que está sendo proferida pelo emissor da mesma.

Isso serviu para nortear o projeto e saber as concepções e principais falhas nesse processo de ensino e aprendizagem. A partir dessa categorização, obtiveram-se quais os tipos de jogos e/ou atividades lúdicas que a turma gostaria de trabalhar.

Os jogos escolhidos foram jogo da memória e cartas, e como atividade lúdica foi o quiz. Com base nisso criou-se um jogo que tentou abranger essas escolhas e que trabalhasse com a dificuldade da turma, relatada por meio do questionário, que era a nomenclatura dos compostos orgânicos.

O jogo foi desenvolvido utilizando recursos disponíveis no campus, como papel adesivo, pincéis atômicos, papéis cartão, folhas de papel vergê, e cartolina. Foram contempladas as funções orgânicas hidrocarbonetos: alcanos, alcenos, alcinos, alcadienos, ciclanos, ciclenos, aromáticos; haletos orgânicos, éter, éster, enol, fenol, ácido carboxílico, aldeído e cetona. 
Figura 1 - Cartas do jogo

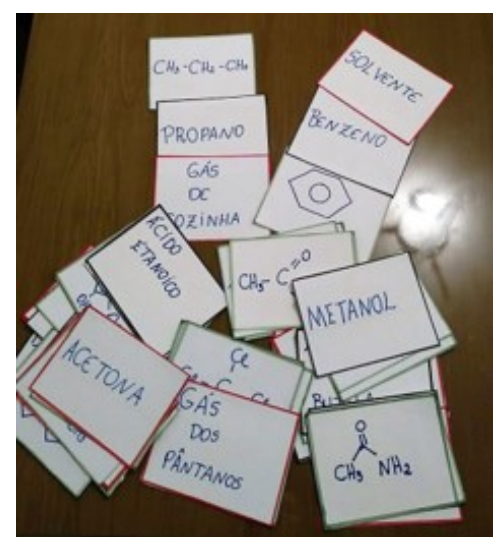

Fonte: Autoria própria (2017).

Para a dinamização do jogo foram confeccionadas cartas sobre a estrutura, nomenclatura e aplicação no cotidiano de cada função orgânica, que foram separadas em três caixas distintas. Para cada função orgânica existiam dois compostos no jogo com estrutura, nomenclatura e aplicação.

A turma foi dividida em dois grupos, cada um deles tinha em uma bancada as três caixas: nomenclatura, estrutura e aplicação. Em cada caixa essas cartas estavam embaralhadas. $O$ objetivo do jogo foi montar no quadro a sequência correta para a função sorteada pegando uma carta de cada caixa. A cada rodada era sorteada uma função que eles deveriam encontrar nas caixas e montar no quadro. A equipe terminava quando todas as suas cartas tivessem acabado. 0 outro grupo deveria fazer a mesma coisa, porém sorteava-se uma ordem diferente de funções orgânicas.

Depois dos dois grupos terem montado suas sequências, cada acerto computava 1 ponto. Ganhava o jogo quem obtivesse mais acertos na construção das relações.

Figura 2 - Desenvolvimento do jogo

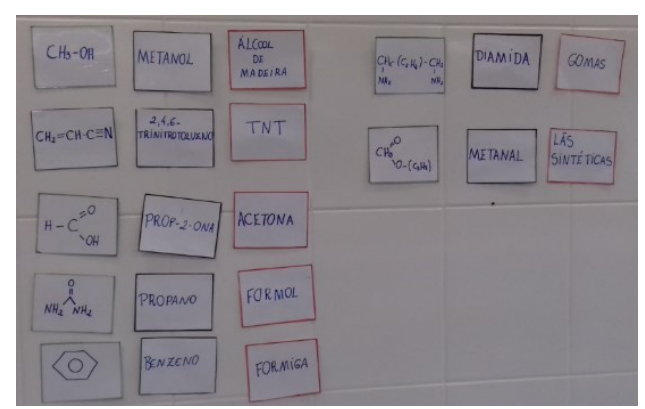

Fonte: Autoria própria (2017).

Também foram desenvolvidas atividades lúdicas com essa turma. Uma delas foi sobre a hibridização do carbono e a geometria das moléculas. Para essa atividade os alunos foram divididos em quatro grupos e cada um recebeu um envelope contendo 6 bexigas e um papel com a fórmula estrutural de determinado composto. $\mathrm{O}$ objetivo dos grupos foi montar a hibridização do carbono presente na fórmula estrutural e apresentar a geometria daquela molécula. Depois que todos os grupos montaram suas geometrias com as bexigas, cada um foi até o quadro e explicou o porquê deles terem montado aquela estrutura com bexigas, apresentando o conceito de hibridização e geometria molecular. 
A outra atividade lúdica realizada com a turma foi sobre isomeria, situação em que os alunos foram distribuídos em seis grupos. Cada equipe recebeu palitos de dente, balas de goma de diferentes cores e um envelope com um tipo de isomeria. Nessa atividade os alunos deveriam montar o tipo de isomeria apresentado no envelope com os palitos de dente e com as balas de goma e apresentar para toda a turma, explicando como chegaram até aquela proposta final.

Figura 3 - Isomeria

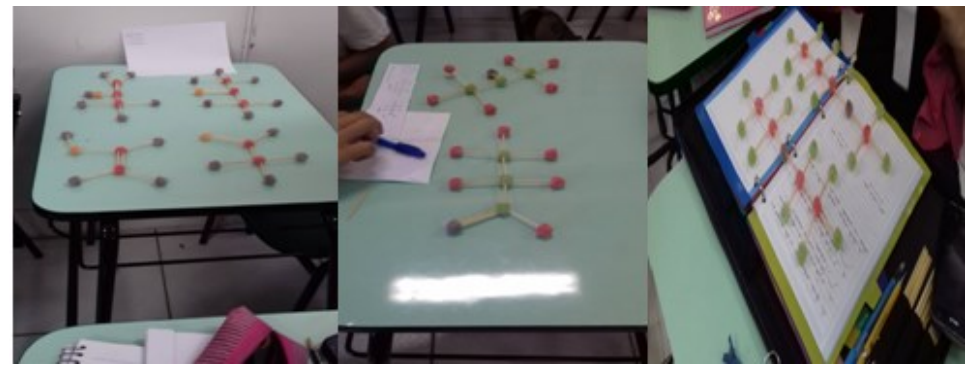

Fonte: Autoria própria (2017).

Depois da aplicação do jogo e das atividades lúdicas os alunos responderam o questionário final para saber se essas ferramentas auxiliaram ou não na aprendizagem em química e as sugestões para desenvolvimento de trabalhos futuros.

\section{RESULTADOS E DISCUSSÃO}

Em relação ao questionamento 1: "Você apresenta dificuldades em relação a disciplina de Química? Se sim, quais são elas?", o objetivo foi conhecer os principais conteúdos que eles apresentavam dificuldades e tentar melhorar a aprendizagem por meio de jogos e atividades lúdicas relacionados às temáticas apresentadas.

As respostas para esta questão foram variadas. Oito alunos relataram dificuldades na nomenclatura de compostos orgânicos e cálculos químicos, os outros responderam que não tinham dificuldades em relação a nenhum conteúdo específico. Em trabalho relatado por Junior e Bizerra (2015) relata-se que um dos assuntos em que os estudantes admitem encontrar maiores dificuldades é o que está relacionado a nomenclatura dos compostos orgânicos, pois envolve um número consideravelmente elevado de informações, uma das possibilidades de justificativa para a resposta dos oito alunos. Isso nos remete para a tentativa de desenvolver estratégias didáticas diferenciadas para trabalhar com esses conteúdos em sala de aula para que possam vir a beneficiar o ensino que poderá ser por meio de jogos e atividades lúdicas.

Para a questão 2: "Como você avalia a metodologia do professor na disciplina de química? Teria alguma sugestão para melhorá-la ou modificá-la? Se sim, quais?", o objetivo foi saber se os alunos aprovam a metodologia utilizada pelo professor e apresentar sugestões para melhorar o processo de ensino e aprendizagem da disciplina de química.

Os alunos avaliaram positivamente a metodologia do professor, trazendo vários elogios em suas respostas, aparecendo apenas quatro sugestões: trazer 
mais documentários; fazer mais exercícios; realizar mais atividades em grupos e mais aulas práticas. Acredita-se que essas respostas reforçam o ato da reflexãoação que o professor dessa turma possui, pois o mesmo vem modificando suas metodologias em sala de aula e isso vem conquistando os alunos para querer aprender química. As sugestões que os alunos apresentaram são relevantes para a melhora ainda mais de seu trabalho em sala de aula.

Na questão 3 perguntou-se: "De acordo com os seus conhecimentos qual seria a definição de jogos didáticos? E qual sua importância para o ensino?", para saber se os alunos conheciam a definição de jogos didáticos e acreditavam que os jogos possuem importância para o ensino de química. Caso eles não soubessem, o intuito era apresentar a eles esse conhecimento para posteriormente trabalhar com os jogos em sua turma.

A maioria dos alunos respondeu conceitos errôneos sobre a definição de jogos didáticos, trazendo a necessidade de trabalhar o conceito com a turma para entenderem as principais diferenças existentes entre jogos e atividades lúdicas.

Para Cunha (2012) é importante diferenciar e definir dois termos: jogo educativo e jogo didático.

O primeiro envolve ações ativas e dinâmicas, permitindo amplas ações na esfera corporal, cognitiva, afetiva e social do estudante, ações essas orientadas pelo professor, podendo ocorrer em diversos locais. O segundo é aquele que está diretamente relacionado ao ensino de conceitos e/ou conteúdos, organizado com regras e atividades programadas e que mantém um equilíbrio entre a função lúdica e a função educativa do jogo, sendo, em geral, realizado na sala de aula ou no laboratório (CUNHA, 2012, p. 95).

Para tornar um pouco mais clara essa diferenciação pode se utilizar como exemplo o jogo da memória ou quebra-cabeças. Os dois, para Cunha (2012), são educativos, pois por meio deles se desenvolvem várias habilidades. Já um jogo didático, além disso, deve possibilitar a aprendizagem de algum conceito. Por exemplo, um jogo de memória orgânica que relaciona os nomes com as fórmulas tem a função do jogo educativo, e é acrescentada a função didática, que é a aprendizagem de conteúdos.

Na turma pesquisada eles souberam responder sobre a importância para o ensino. Obteve-se respostas que foram agrupadas por semelhança e algumas são apresentadas como exemplo no quadro 1.

Quadro 1 - Importância dos jogos no ensino

\begin{tabular}{|c|c|}
\hline $\begin{array}{l}\text { Unidade de } \\
\text { significado }\end{array}$ & Exemplos de respostas \\
\hline Aprendizagem & $\begin{array}{l}\text { "Desperta o interesse dos alunos ajudando a querer aprender mais e } \\
\text { mais." (A43) }\end{array}$ \\
\hline Raciocínio & “Para o melhor desenvolvimento do raciocínio." (A5) \\
\hline Sociabilidade & "Acho que os jogos nos ajudam a ser menos antissociais." (A29) \\
\hline Divertimento & $\begin{array}{l}\text { "Acho que é importante brincar aprendendo, deixam as coisas mais } \\
\text { descontraídas." (A41) }\end{array}$ \\
\hline Conteúdo & $\begin{array}{l}\text { "Eles são importantes porque ajudam algumas pessoas a entenderem } \\
\text { a matéria." (A44) }\end{array}$ \\
\hline
\end{tabular}

Fonte: Autoria própria (2017). 
A importância dos jogos no ensino é diversificada, pois "têm função relacionada à aprendizagem de conceitos, não sendo uma atividade totalmente livre e descomprometida, mas uma atividade intencional e orientada pelo professor" (CUNHA, 2012, p. 95). Percebe-se pelas respostas dos alunos a importância que o jogo pode proporcionar. Para Tezani (2006), o jogo é essencial como recurso pedagógico, pois é no brincar que a criança articula teoria, prática e formula hipóteses, para tornar a aprendizagem atrativa e interessante. Isso pode ser reafirmado pela resposta do aluno A41.

A questão 4 perguntava: “Em sua opinião o uso de jogos didáticos e atividades lúdicas podem auxiliar na aprendizagem na disciplina de química? Independente se sua resposta foi positiva ou negativa, explique-a." O objetivo desta foi saber se os alunos acreditavam que os jogos e atividades lúdicas auxiliarão na aprendizagem, pois se a devolutiva da maioria fosse negativa não havia motivos de fazer a aplicação no projeto na turma. E se a devolutiva fosse positiva, saber o porquê auxiliaria na aprendizagem de química.

Das respostas obtidas $83 \%$ dos alunos responderam que os jogos podem auxiliar no processo de ensino; $13 \%$ não responderam à questão e $4 \%$ acreditam que os jogos não vão auxiliar na aprendizagem. Nessa questão, a maioria dos alunos respondeu que os jogos iriam auxiliar porque eles são mais divertidos; a aula se torna diferente; é mais legal; e possui interação com os colegas. Isso vai ao encontro do que Kishimoto (1994) descreve sobre a função lúdica estar relacionada ao caráter de diversão e prazer que o jogo propicia. A educativa se refere à apreensão de conhecimentos, habilidade e saberes.

Entende-se que o jogo de regras é uma conduta lúdica que supõe relações entre os indivíduos, pressupõe a existência de parcerias e de certas obrigações comuns. Portanto, a atividade lúdica é socializada. Assim, esta atividade não pode ser um passatempo, mas um universo rico e fundamental para o desenvolvimento infantil, "o qual se torna um elemento que integra os vários aspectos da personalidade: afetivo, motor, cognitivo, cultural e social" (SANTOS, 2008). Fato este relacionado as respostas que os alunos colocaram da interação com os colegas.

Na questão 5 perguntou-se: "Como forma de diversificar o ensino utilizam-se os jogos didáticos e atividades lúdicas em sala de aula em várias disciplinas. Você gostaria de utilizá-los no ensino de química?". Desta vez a ideia era saber se os alunos gostariam de utilizar dessa metodologia nas suas aulas de química, pois se não quisessem não iríamos aplicar nessas turmas. 0 resultado está apresentado na figura 4 abaixo. 
Figura 4 - Utilização de jogos na disciplina de química

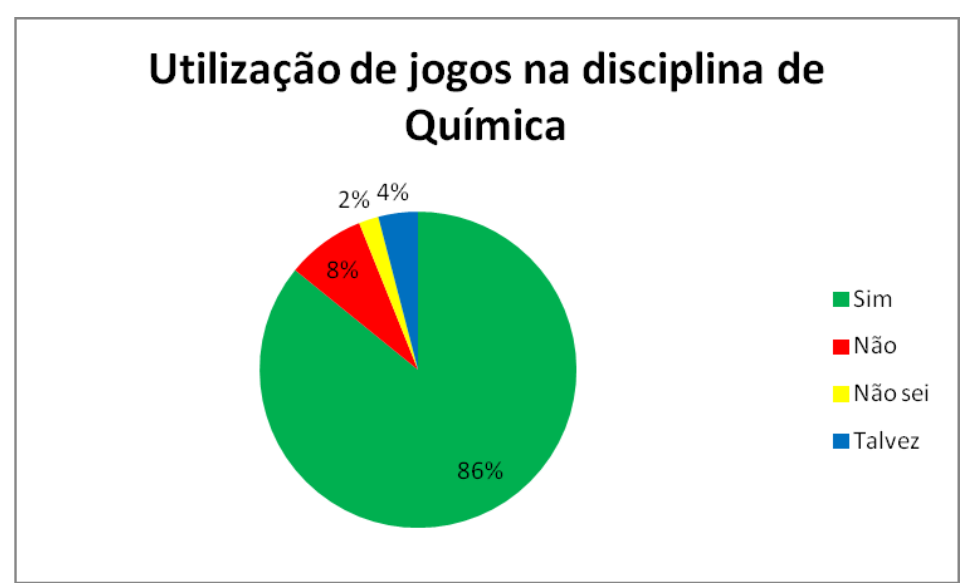

Fonte: Autoria própria (2017).

Essas respostas reforçam ainda mais a necessidade de tentar modificar as aulas tradicionalmente aplicadas na maioria das escolas, para metodologias diversificadas que irão incentivar a aprendizagem e o gosto de nossos alunos pelas disciplinas de ciências.

Quando o adolescente joga ele acaba comprometendo toda sua personalidade, tem a impressão de que o tempo não passa. Pode-se dizer então que faz com que $o$ adolescente dedique-se com prazer e verdadeiramente com o jogo aplicado. "O jogo ajuda este a construir novas formas de pensamento, desenvolvendo e enriquecendo sua personalidade" (CUNHA, 2012, p. 92).

Neves e Pereira (2006) apontam alguns benefícios da utilização de jogos como ferramenta metodológica de apoio ao ensino e aprendizagem:

\footnotetext{
- conseguimos detectar os alunos que estão com dificuldades reais;

- os alunos demonstram para seus colegas e professores se o assunto foi bem assimilado;
}

- existe uma competição entre os jogadores e os adversários, pois almejam vencer e, por isso, aperfeiçoam-se e ultrapassam seus limites;
- durante o desenrolar do jogo, observa-se que o aluno torna-se mais crítico, alerta e confiante, expressando o que pensa, elaborando perguntas e tirando conclusões sem a necessidade ou aprovação do professor;

- não existe o medo de errar, pois o erro é considerado um degrau necessário para se chegar a uma resposta correta;

- o aluno se empolga com o clima de uma aula diferente, o que faz com que aprenda sem perceber (NEVES; PEREIRA, 2006, p. 99).

Para a questão 6 solicitou-se que: "Se sua resposta foi sim a questão anterior, qual (is) dos tipos de jogos e atividades lúdicas abaixo você mais gostaria de realizar?
( ) Ludo
( ) Jogo da Memória
( ) Cruzadinha
( ) Cartas
( ) Quiz
( ) Jogos de tabuleiro
( ) Outros (especifique)" 
O objetivo dessa questão foi delimitar e delinear quais jogos e atividades lúdicas seriam trabalhadas, sendo que os alunos optaram por jogo da memória, quiz e cartas, conforme já foi mencionado.

Como já exposto, foi desenvolvido e aplicado um jogo que tentou trabalhar com as dificuldades apontadas pelos alunos nas respostas dos questionários e do tipo de jogo que os mesmos preferiam desenvolver de acordo com a resposta da questão 6 do questionário inicial.

Depois do desenvolvimento do jogo para trabalhar as funções orgânicas, sua nomenclatura e aplicações no cotidiano, passou-se para sua aplicação.

Após a aplicação do jogo elaborou-se um questionário final para verificar quais as possíveis contribuições que o jogo conseguiu alcançar e identificar as falhas e sugestões de aprimoramento do trabalho.

No questionário final foram feitas várias perguntas, entre elas destaca-se: “O que você achou do jogo aplicado?". O resultado da análise dessa questão está expresso na figura 5 .

Figura 5 - Percepções sobre o jogo aplicado

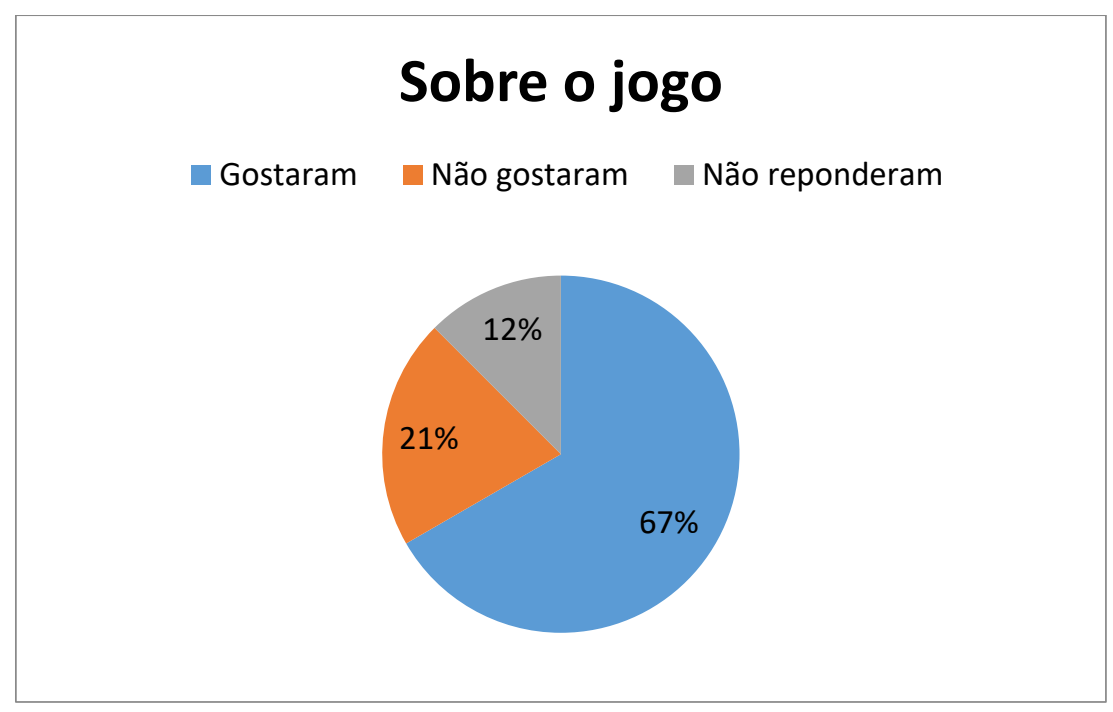

Fonte: Autoria própria (2017).

Pelos dados expressos por meio desse gráfico consegue-se identificar que um dos objetivos do jogo e do projeto, ou seja, de que os alunos gostassem da metodologia aplicada, foi contemplado com $67 \%$ dos alunos que responderam ao questionário. Porém, não podemos somente com essa questão saber se os alunos aprenderam ou não os conceitos trabalhados pelo jogo, pois é preciso ir além, "precisamos mostrar em nossas discussões, como o jogo de fato auxiliou na apreensão do conceito pretendido" (SOARES, 2016, p. 12). Isso poderá ser obervado pelas discussões em relação a outras questões, o que será realizado posteriormente.

Outra questão presente no questionário final foi:"Durante o jogo qual foi sua maior dificuldade?". A análise quantitativa em relação a essa questão está demonstrada na figura 6 . As dificuldades apontadas pelos alunos demonstram falta de atenção em responder ao questionário e também em relembrar os conteúdos trabalhados pelo professor. 
Figura 6 - Dificuldades apresentadas durante a aplicação do jogo

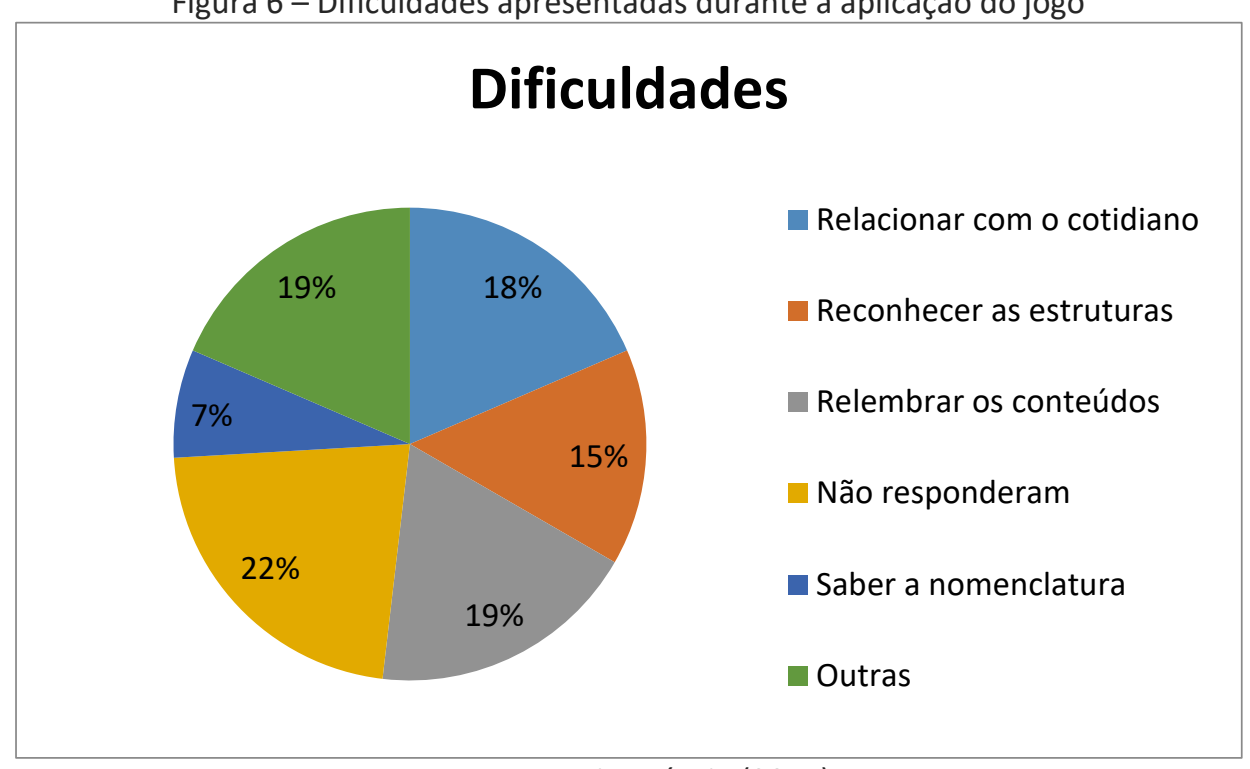

Fonte: Autoria própria (2017).

Mesmo o professor tendo trabalhado em suas aulas as funções orgânicas e suas aplicações no cotidiano, $18 \%$ dos alunos que responderam ao questionário relataram que sentiram dificuldades nesse sentido. Quando o professor aplica situações do cotidiano ele utiliza de um recurso para tentar relacionar o ensino de conteúdos relacionados a fenômenos que ocorrem na vida diária dos indivíduos com vistas à aprendizagem de conceitos (DELIZOICOV; ANGOTTI; PERNAMBUCO, 2002, SANTOS; MORTIMER, 1999). Acreditamos que o professor deverá trabalhar ainda mais essas situações com seus alunos, pois, para alguns alunos, o jogo ainda não conseguiu relacionar com as situações do cotidiano apresentada durante as aulas.

Uma das questões que gerou resultados importantes para serem discutidos foi: "O que você mais gostou no Jogo? E o que menos gostou?". Tentou-se estabelecer pontos de convergência e divergência entre as respostas dos alunos. Depois, agruparam-se as respostas mais convergentes (apresentadas nas figuras 7 e 8).

Dos alunos participantes do estudo, $21 \%$ não responderam à pergunta, e outros $21 \%$ indicaram que gostaram do jogo por sua forma de interação. Pelas respostas apresentadas pode-se demonstrar a importância que o jogo possui como elo para o desenvolvimento intelectual dos alunos.

Esse resultado corrobora com Facetola et al. (2012) quando descreve que o jogo não pode ser considerado como única ferramenta de ensino, mas apresentase como uma maneira mais harmônica para que os alunos estabeleçam a interação entre eles, e assim se tornem mais ativos na construção do próprio saber.

Outro aspecto ressaltado pelas respostas dos alunos foi o trabalho em equipe. A proposta da utilização de jogo didático no ensino de Química segundo Campos (2006) visa a desenvolver a autonomia, beneficiar a elaboração da subjetividade, a ampliação da competência de iniciativa, a capacidade de criar e a habilidade de trabalho em equipe, ponto este que vai ao encontro com a proposta do projeto. 
Figura 7 - Características que mais gostaram no jogo

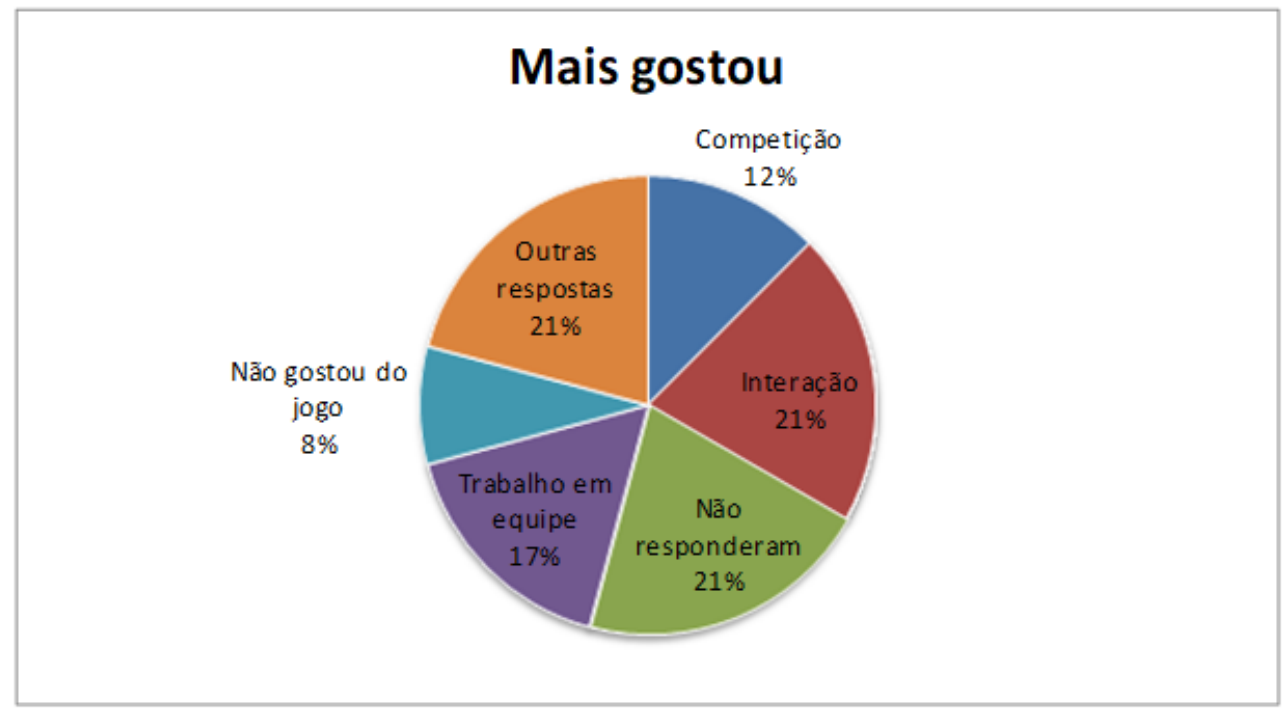

Fonte: Autoria própria (2017).

Nesse sentido cabe ao professor "colaborar com a elaboração de conceitos, reforçar conteúdos, promover a sociabilidade entre os alunos, trabalhar a criatividade, o espírito de competição e a cooperação" (FIALHO, 2007, p. 16). A competição foi uma das características positivas apontadas pelos alunos com a utilização do jogo que corrobora com a literatura consultada.

Figura 8 - Características que menos gostaram no jogo

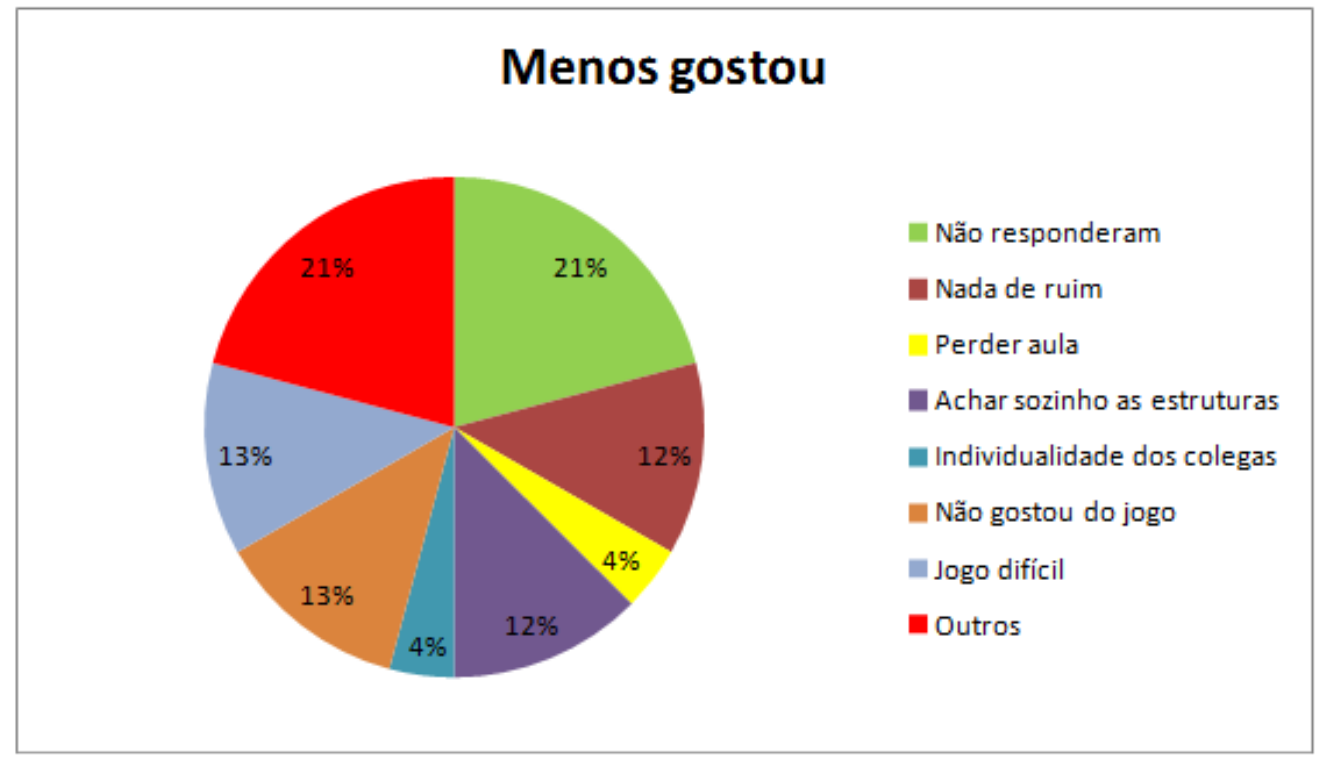

Fonte: Autoria própria (2017).

Para 13\% dos alunos que responderam o questionário o jogo foi caracterizado como difícil. Isso pode ser devido aos alunos terem relatado na figura 7 que não conseguiram relembrar os conteúdos trabalhados pelo professor.

Essa dificuldade é apontada por Souza e Silva (2012), a proposta de um jogo didático como forma de contribuir para o processo de ensino-aprendizagem no ensino de nomenclatura dos compostos orgânicos, na medida em que o tema funções orgânicas é de entendimento complexo, pois os alunos não apresentam a 
habilidade de associar facilmente a estrutura ao nome correspondente à função. Um fator negativo para a análise do questionário em relação a essa pergunta é que $21 \%$ dos alunos não responderam essa questão.

Uma das questões que compunha o questionário foi "Você acredita que esse jogo pode ser adaptado para outras disciplinas? Se sim, em quais?". Para $71 \%$ dos alunos os jogos poderiam ser aplicados em outras disciplinas; $12 \%$ não poderiam ser aplicados; $13 \%$ não responderam e $4 \%$ relataram não saber. As disciplinas em que os alunos acreditam que poderiam ser aplicados os jogos foram: física, português, biologia, inglês, história e lógica de programação.

A única disciplina da área técnica do curso estudado em que os alunos relataram que poderia ser utilizado os jogos foi a lógica de programação. Isso vai ao encontro das propostas que Barbosa (2011) traz, já que essa disciplina exige uma nova forma de pensar e requer certas habilidades que não foram desenvolvidas, levando os alunos a terem grandes dificuldades e mau desempenho durante o curso.

Em relação às duas atividades lúdicas que foram trabalhadas com a turma (hibridização do carbono e a geometria das moléculas; isomeria), os alunos relataram ter gostado das atividades, pois as mesmas trouxeram os conteúdos de forma mais dinâmica e diferente do que é apresentada usualmente no ensino de química.

Essas observações corroboram com Soares (2004), quando utiliza uma comparação de interação entre jogo e jogador com o uso de atividades lúdicas. Entre elas pode-se citar:

\begin{abstract}
Construção de modelos e protótipos que se baseiem em modelos teóricos vigentes, como forma de manipulação palpável do conhecimento teórico. [...] Em síntese, esse nível é aquele em que se manipula um material como um brinquedo (SOARES, 2004, p. 54).
\end{abstract}

Esse foi o tipo de atividade lúdica que os alunos realizaram quando manipularam as bexigas e os palitos de dente com as balas de goma, pois fizeram a manipulação desse material com base nos modelos teóricos trabalhados em sala de aula pelo professor, fazendo com que eles trabalhassem o conceito de forma lúdica, com a manipulação dos materiais funcionando como se fossem seus brinquedos.

\title{
CONSIDERAÇÕES FINAIS
}

Pelas respostas expressas no questionário inicial pode-se concluir que os alunos possuem algumas dificuldades em relação aos conteúdos de nomenclatura de compostos orgânicos. Para tentar diminuir essas dificuldades foram propostos o jogo e as atividades lúdicas trabalhadas com os alunos, como forma diversificada de metodologia de ensino.

Em relação à metodologia do professor, a maioria dos alunos avaliou positivamente e sugeriram algumas ações para melhorar ainda mais as aulas, como documentários; realizar mais atividades em grupos e aulas práticas.

Para a questão sobre a definição sobre jogos didáticos a maioria dos alunos não soube explicar e isso tentou ser sanado por meio de seminários que o aluno 
bolsista realizou para a turma, apresentando o conceito e as suas principais diferenciações, para depois aplicação do jogo e das atividades lúdicas. Infelizmente mesmo após esse trabalho alguns alunos ainda não sabiam explicar e diferenciálos.

Sobre a utilização de jogos e atividades lúdicas para a aprendizagem de conceitos, a maioria dos alunos acredita que eles podem auxiliar, pois deixam as aulas mais dinâmicas, há mais interação com os colegas e podem vir a auxiliar na aprendizagem dos conteúdos. Esses resultados reforçam ainda mais a necessidade de implantar metodologias diversificadas nas aulas de ciências/química e também irão auxiliar para execução de outros projetos na instituição de ensino.

Para a maioria dos alunos que participaram do projeto os jogos e as atividades lúdicas auxiliaram no processo de ensino. Sabe-se que a atividade lúdica motiva os alunos a quererem aprender, fazendo com que ela seja uma ferramenta auxiliadora no processo de ensino e aprendizagem. Dentro deste tema deixa-se a sugestão para trabalhos futuros, os quais venham confirmar essa ferramenta como objeto de estudo.

A importância de conhecer os tipos de jogos e atividades lúdicas que a turma gostaria de desenvolver no projeto serviu para nortear o trabalho da elaboração e confecção dos mesmos, e também para saber a realidade dos alunos, que tipos de jogos estão presentes no cotidiano deles.

O jogo e as atividades lúdicas aplicadas segundo respostas dadas pelos alunos que participaram do projeto desenvolveu neles a capacidade de maior interação com os colegas, a competitividade, habilidade de trabalho em equipe. Pontos estes que corroboram com a literatura sobre a ludicidade e o seu papel no ensino.

Para os alunos que participaram do projeto os jogos e as atividades lúdicas podem ser aplicados em outras disciplinas como física, português, biologia, inglês, entre outras e também em uma disciplina técnica chamada lógica de programação. Isso pode tornar o ensino dessas disciplinas mais interessante para os alunos e auxiliar na aprendizagem dos conceitos trabalhados pelo professor.

Um ponto que merece destaque para os trabalhos futuros é testar em que nível de conhecimento encontra-se o conteúdo do jogo, pois alguns alunos relataram que acharam-no difícil. Outro ponto é não somente saber se os alunos gostaram ou não dos jogos e das atividades lúdicas desenvolvidas, mas sim trabalhar com teorias de aprendizagem e as suas relações com a ludicidade. 


\title{
The use of playfulness as a tool for organic chemistry education: what students think
}

\begin{abstract}
For most students the discipline of chemistry is very theoretical, monotonous, with many calculations and most of the time has no interaction with their daily life. There are many tools that can help to make the teaching and learning process more meaningful and more attractive to students, one of these ways is through games and play activities. These were the tools chosen to develop a PIBIC-Jr project at the IFPR Campus Telêmaco Borba during the year 2016. The present study deals with the development, application and evaluation of a didactic game and two ludic activities for the teaching of chemistry Organic for a class of 3rd year of the Technician in Computing for Internet Integrated to High School. The results were analyzed through questionnaire responses and later categorized for the analysis of the results. This show that play and ludic activities could help in the teaching and learning process, and also showed that these tools facilitated a greater dialogue and interaction among the students.
\end{abstract}

KEYWORDS: Chemistry education. Playful. Organic chemistry. 


\section{AGRADECIMENTOS}

Os autores agradecem aos alunos que participaram do desenvolvimento do projeto, ao CNPq pela bolsa concedida pelo processo 302281/2015-0.

\section{REFERÊNCIAS}

BARBOSA, L., S., Aprendizado Significativo Aplicado ao Ensino de Algoritmos, 2011. 57f. Dissertação (Pós-Graduação em Sistemas de Computação) Departamento de Informática e Matemática Aplicada. Universidade Federal do Rio Grande do Norte, 2011. Disponível em: https://repositorio.ufrn.br/ispui/bitstream/123456789/18018/1/LeonidasSB DIS SERT.pdf. Acesso em: 23 mai. 2017.

BARDIN, L. Análise de Conteúdo. Lisboa, Portugal; Edições 70, LDA, 2002.

CUNHA, M.B. da, Jogos no Ensino de Química: Considerações Teóricas para sua Utilização em Sala de Aula, Química Nova na Escola, v. 34, n² 2, p. 92-98, mai., 2012. Disponível em: http://qnesc.sbq.org.br/online/qnesc34 2/07-PE-53-11.pdf. Acesso em: 10 jun. 2017.

DELIZOICOV, D.; ANGOTTI, J. A.; PERNAMBUCO, M. M. Ensino de Ciências: fundamentos e métodos, 3a ed. São Paulo: Cortez, 2002.

FACETOLA, P. B. M.; CASTRO, P. J.; SOUZA, A. C. J.; GRION, L. S., PEDRO, N. C. S.; IACK, R. S.; ALMEIDA, R. X., OLIVEIRA, A.C.; BARROS, C.; VARGAS T.; VASTMAN, E.; BRANDÃO, J. B.; GUERRA, A. C. O.; DA SILVA, J. F. M., Os Jogos Educacionais de Cartas como estratégia de Ensino em Química, Química Nova na Escola, v. 34, p.248-255, nov., 2012. Disponível em:

http://anesc.sbq.org.br/online/qnesc34 4/11-PIBID-44-12.pdf. Acesso em: 15 jul. 2017.

FIALHO, N. N. Jogos no Ensino de Química e Biologia. Curitiba: IBPEX, 2007.

FIORENTINI, D.; LORENZATO, S. Investigação em educação matemática: percursos teóricos e metodológicos. 3. ed. Ver. Campinas: Autores Associados, 2009.

JÚNIOR, C. A. B. S.; BIZERRA, A. M. C., Estruturas e nomenclaturas dos hidrocarbonetos: é possível aprender jogando?, Holos, Ano 31, v. 6, p. 146-155, 2015. Disponível em:

http://www2.ifrn.edu.br/ojs/index.php/HOLOS/article/view/3616/1219. Acesso em: 27 jul. 2017. 
KISHIMOTO, T.M. O jogo e a educação infantil. Perspectiva. Florianópolis, UFSC/CED, NUP, n. 22, p. 105-128, 1994. Disponível em:

https://periodicos.ufsc.br/index.php/perspectiva/article/download/10745/10260 Acesso em: 25 jul. 2017.

MOREIRA, H; CALEFFE, L. G. Metodologia da pesquisa para o professor pesquisador. Rio de Janeiro: Lamparina, 2008.

NEVES, M. C. D; PEREIRA, R. F. Divulgando a ciência: de brinquedos, jogos e do voo humano. 1. ed. - Maringá: Massoni, 2006.

OLIVEIRA, J. S.; SOARES, M. H. F. B.; VAZ, W. F., Banco Químico: um Jogo de Tabuleiro, Cartas, Dados, Compras e Vendas para o Ensino do Conceito de Soluções, Química Nova na Escola, v. 37, n 4, p. 285-293, nov., 2015. Disponível em: http://anesc.sbq.org.br/online/anesc37 4/08-RSA-22-13.pdf. Acesso em: 10 jul. 2017.

PAZINATO M. S.; BRAIBANTE H. T. S.; BRAIBANTE M. E. F; TREVISAN M. C.; SILVA G. S., Uma Abordagem Diferenciada para o Ensino de Funções Orgânicas através da Temática Medicamentos, Química Nova na Escola, v. 34, n 1, p. 21- 25, fevereiro, 2012. Disponível em: http://qnesc.sbq.org.br/online/anesc34 1/05-EA43-11.pdf. Acesso em: 20 jul. 2017.

SANTOS, S. M. P. A Ludicidade como Ciência. 2aㅡ Ed. Petrópolis - RJ, Editora Vozes, 2008.

SANTOS, W.L.P. e MORTIMER, E.F. Concepções de professores sobre contextualização social do ensino de química e ciências. In: Reunião anual da sociedade brasileira de química, 22, 1999. Anais... Poços de Caldas: Sociedade Brasileira de Química, 1999.

SOARES, M. H. F. B., Jogos e Atividades Lúdicas no Ensino de Química, 2004, 203f. Tese (Doutorado em Química), Universidade Federal de São Carlos, São Carlos, SP, 2004. Disponível em: https://repositorio.ufscar.br/bitstream/handle/ufscar/6215/4088.pdf?sequence= 1\&isAllowed=y. Acesso em: 26 nov. 2016.

SOARES, M. H. F. B.; Jogos e Atividades Lúdicas para o Ensino de Química. Goiânia: Kelps, 2013. discussão teórica necessária para novos avanços, Redequim, v.2, № 2, outubro, p. 5-13, 2016. Disponível em: 
http://www.journals.ufrpe.br/index.php/REDEQUIM/article/view/1311/1071. Acesso em: 12 jan. 2017.

SOLOMONS, T. W. G. FRYHLE, C.B; Química Orgânica. 8ª ed. Rio de Janeiro: Livros Técnicos e Científicos, 2005.

SOUZA, H. Y. S.; SILVA C. K. O., Dados Orgânicos: Um Jogo Didático no Ensino de Química, Holos, Ano 28, v. 3, p. 107-121, 2012. Disponível em: http://www2.ifrn.edu.br/ojs/index.php/HOLOS/article/view/737/559. Acesso em: 15 jul. 2017.

TEZANI, T.C.R., O jogo e os processos de aprendizagem e desenvolvimento: aspectos cognitivos e afetivos. Educação em Revista, Marília, v.7, n.1/2, p. 1- 16, 2006. Disponível em:

http://www2.marilia.unesp.br/revistas/index.php/educacaoemrevista/article/vie w/603/486. Acesso em: 20 jun. 2017.

Recebido: 29 mai. 2017

Aprovado: 25 set. 2017

DOI: $10.3895 /$ actio.v2n2.6810

Como citar:

RAMOS, E. S.; SANTOS, F. A. C.; LABURÚ, C. E. O uso da ludicidade como ferramenta para o Ensino de Quimica Organica: o que pensam os alunos. ACTIO, Curitiba, v. 2, n. 1, p. 119-136, jan./jul. 2017. Disponível em: <https://periodicos.utfpr.edu.br/actio>. Acesso em: XXX.

Correspondência:

Elaine da Silva Ramos

Avenida Antônio Saad, 2500 - Casa 175 - Condomínio Terra Nova, Boa Vista, Ponta Grossa, Paraná, Brasil.

Direito autoral: Este artigo está licenciado sob os termos da Licença CreativeCommons-Atribuição 4.0

Internacional.

(c) (i) 